\title{
Tratamiento híbrido de arteria subclavia derecha aberrante*
}

\author{
Drs. FRANCISCO VARGAS S. ${ }^{1}$, RENATO MERTENS M. ${ }^{1}$, GONZALO SÁNCHEZ C. ${ }^{1}$, \\ MICHEL BERGOEING R. ${ }^{1}$, ALBRECHT KRÄMER S. ${ }^{1}$, \\ LEOPOLDO MARINÉ M.', FRANCISCO VALDÉS E. ${ }^{1}$
}

1 Departamento de Cirugía Vascular y Endovascular, Pontificia Universidad Católica. Santiago, Chile.

Abstract

\section{Hybrid treatment aberrant right subclavian artery}

Introduction: An aberrant right subclavian artery is the most frequent aortic arch malformation. It is frequently an incidental finding of imaging studies and serious complications may arise if left untreated. Clinical case: We present a case of a young woman with a dilated aberrant right subclavian artery that was successfully treated by a hybrid approach.

Key words: Lusoria artery, aberrant subclavian artery, endovascular, hybrid treatment.

\section{Resumen}

Introducción: La arteria subclavia derecha aberrante es la malformación arterial más frecuente del arco aórtico. Su diagnóstico es habitualmente un hallazgo de estudios de imágenes solicitados por otras causas pero puede tener serias complicaciones si se obtiene en forma tardía. Caso clínico: Presentamos el caso de una mujer joven con diagnóstico de arteria subclavia lusoria dilatada sometida exitosamente a tratamiento híbrido electivo. híbrido.

Palabras clave: Arteria lusoria, arteria subclavia aberrante, tratamiento endovascular, tratamiento

\section{Caso clínico}

Presentamos el caso de una mujer de 22 años, esencialmente sana, con crisis episódicas de cefalea hemicránea derecha desde hace dos años. En ese contexto fue estudiada con tomografía axial computada cerebral pesquisándose displasia fibromuscular de carótida interna derecha distal. Estudio posterior con tomografía axial computada en fase arterial evidenció además displasia de arteria subclavia derecha y arterias carótidas interna y externa del mismo lado. Además se objetivó persistencia de arteria subclavia lusoria con dilatación aneurismática de aproximadamente 2,5 cm de diámetro mayor (Figura 1).

Fue hospitalizada electivamente para completar tratamiento híbrido de su malformación en dos tiempos.

*Recibido el 18 de agosto de 2012 y aceptado el 29 de septiembre de 2012.

Los autores no refieren conflictos de interés.

Correspondencia: Dr. Francisco Vargas S.

Marcoleta 367, $8^{\circ}$ Piso, Santiago, Chile.

jfvargas@gmail.com 


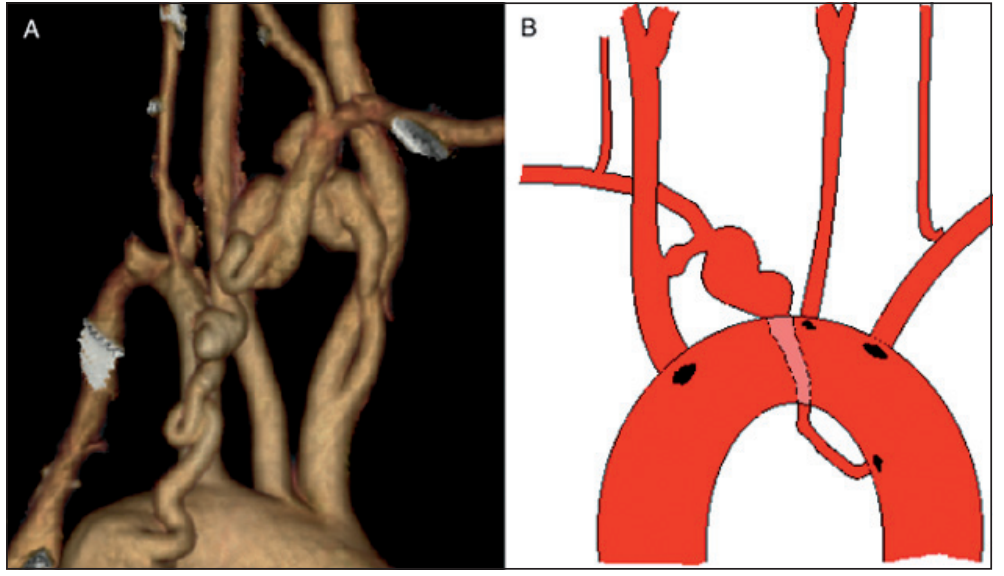

Figura 1. A) Reconstrucción tridimensional de tomografía axial computada en fase arterial tomada previo a tratamiento (vista posterior). B) Esquema de la malformación arterial de la paciente (vista anterior).
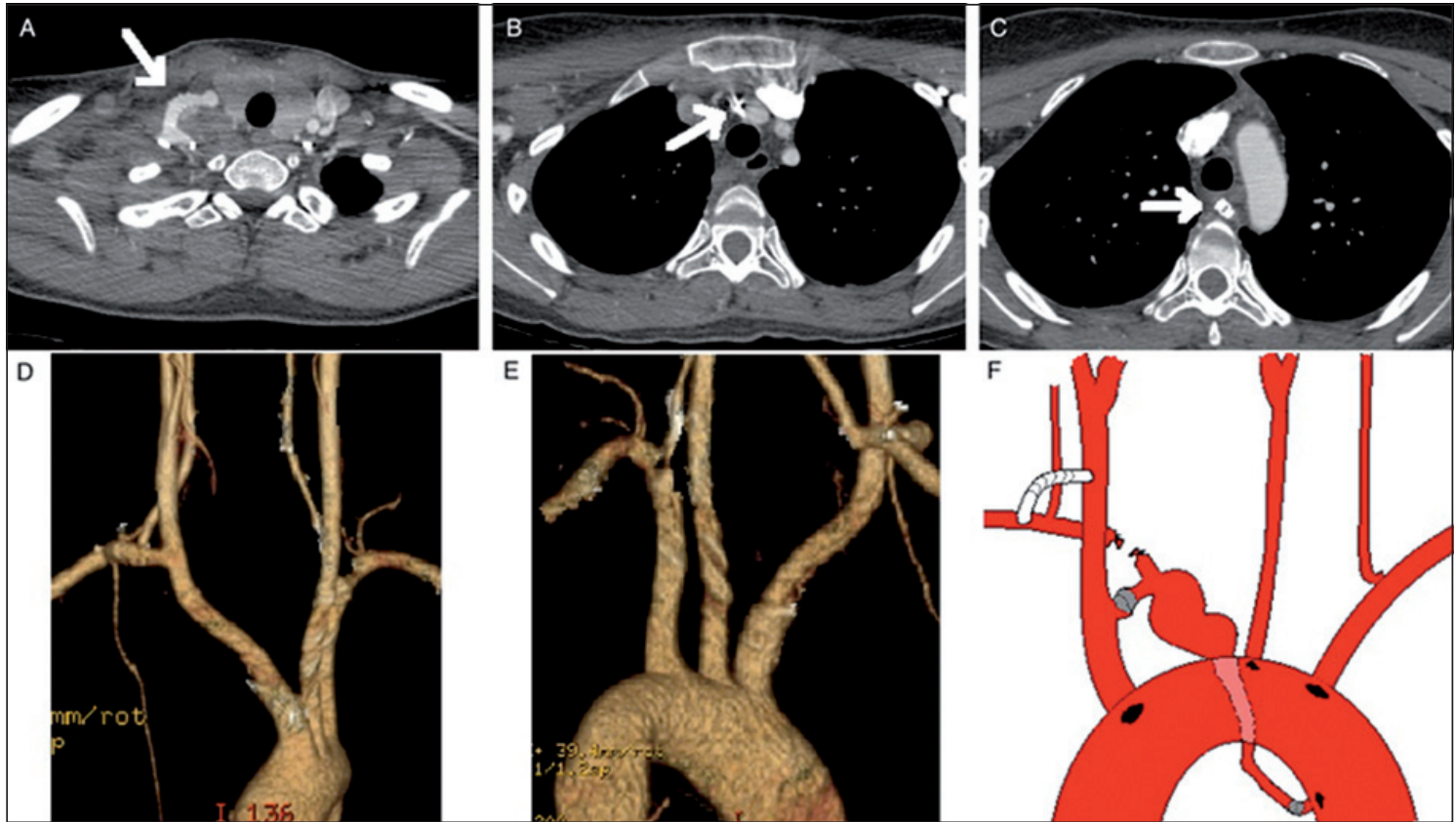

Figura 2. A, B, C) Cortes axiales de tomografía axial computada en fase arterial tomada posterior al tratamiento (A: Bypass carotídeo subclavio derecho, B: Amplatzer en unión de arteria subclavia con tronco braquiocefálico, C: Amplatzer en origen de arteria lusoria a nivel del arco aórtico). D y E) Reconstrucción tridimensional de tomografía axial computada en fase arterial tomada posterior a tratamiento (D: vista anterior, E: vista posterior). F) Esquema del tratamiento híbrido completado (vista anterior).

Se confeccionó bypass carotídeo subclavio derecho sin incidentes utilizando una prótesis de PTFE anillado de $6 \mathrm{~mm}$. En el mismo tiempo quirúrgico se realizó ligadura de la arteria subclavia proximal al origen de la arteria vertebral.

Al día siguiente se procedió a ocluir la arteria lusoria en sus extremos por vía femoral derecha a través de vaina Rabee de 6 Fr; oclusor Amplatzerä Vascular Plug II de $8 \mathrm{~mm}$ a nivel de la unión con tronco braquiocefálico y otro similar de $6 \mathrm{~mm}$ a nivel del origen en aorta descendente (Figura 2).

Tuvo evolución postoperatoria sin incidentes, siendo dada de alta al cuarto día, y actualmente se encuentra en seguimiento sin complicaciones. 


\section{Discusión}

La arteria subclavia aberrante es la anomalía más frecuente del desarrollo del arco aórtico ${ }^{1}$. Su incidencia reportada en la literatura va desde 0,4 hasta $2,3 \%{ }^{2}$.

A lo largo del desarrollo vascular del embrión se producen múltiples y complejas remodelaciones y regresiones. Alteraciones de estos procesos llevan a la posibilidad de presentar innumerables variaciones anatómicas ${ }^{3}$. Se cree que el origen de esta malformación ocurre por involución del IV arco aórtico derecho con persistencia de la séptima arteria intersegmental derecha ${ }^{4}$.

Estas arterias aberrantes tienden a dilatarse y pueden complicarse con fenómenos tromboembólicos de la extremidad superior derecha o con ruptura; la que se asocia a altas tasas de mortalidad; incluso mayor a $50 \%{ }^{5}$. Además puede asociarse a otras alteraciones del desarrollo del arco aórtico o de la aorta descendente; como coartación aórtica ${ }^{6}$.

Habitualmente son asintomáticas y se detectan como hallazgo en exámenes imagenológicos realizados por otras causas. Cuando presentan síntomas; éstos son variables y van desde molestias inespecíficas hasta dolor torácico o tos. El síntoma típico por el cual esta malformación fue descrita inicialmente es la disfagia que, cuando causada por la compresión del esófago por la subclavia aberrante aneurismática contra la columna o la traquea, se denomina disfagia lusoria ${ }^{2}$. El origen de este término se remonta al año 1794, en que fue descrita por el médico londinense David Bayford como una "disfagia por capricho de la naturaleza" o de lusus naturae ${ }^{3}$.

La malformación arterial descrita en este caso tiene la particularidad de ser una arteria subclavia derecha aberrante pero con persistencia de su conexión con el tronco braquiocefálico. Por esta razón fue necesario realizar la exclusión de la arteria aneurismática en los tres puntos ya descritos.

Cuando se produce una dilatación aneurismática de la arteria aberrante existe alto riesgo de complicaciones tromboembólicas y de mortalidad. Estas no se han podido relacionar con algún tamaño bajo el cual sería razonable sólo observar; por lo que incluso se ha planteado el tratamiento de cualquier arteria subclavia aberrante dilatada, independiente de su diámetro $^{5}$. Los tratamientos descritos tradicionalmente son la cirugía mediante toracotomía o esternotomía, pudiendo requerir circulación extracorpórea, que tienen elevadas tasas de morbimortalidad de hasta $25 \%{ }^{7}$. Desde su descripción por Lacroix et al, en el 2003, se han descrito múltiples casos de resolución híbrida combinando procedimientos abiertos con cirugía endovascular logrando disminuir significativamente las tasas de morbimortalidad operatorias ${ }^{8}$.

Existe el riesgo ya descrito de presentar síntomas por isquemia de la extremidad superior derecha al ocluir la arteria anómala ${ }^{9}$, por lo que se ha planteado la necesidad de revascularizar dicha extremidad previo a la oclusión; lo que se realizó en nuestra paciente.

Pensamos que el tratamiento endovascular/híbrido de esta patología debiera ser el tratamiento de elección. Minimiza la morbimortalidad potencial que acompaña una eventual toracotomía en caso de escogerse el abordaje directo.

\section{Referencias}

1. Richardson J V, Doty D B, Rossi N P, Ehrenhaft J L. Operation for aortic arch anomalies. Ann Thorac Surg. 1981;31:426-32.

2. Agrawal H, Volkmann ER. Aberrant right subclavian artery aneurysm. Intern Med J. 2011;41:641-2.

3. Insunza O, Burdiles A. Aberrant Subclavian Artery. International Journal of Morphology 2010;28:1215-9.

4. Moore KL, Perdaud TV. The Developing Human: Clinical Embriology. 7th ed. Philadelphia, Pennsylvania: Saunders, 1999:360-3.

5. Ferrero E, Ferri M, Viazzo A, Carbonatto P, Pecchio A, Casabona R, et al. Aneurysm of the aberrant right subclavian artery: surgical and hybrid repair of two cases in a single center. Ann Vasc Surg. 2011;25:839 e835-9.

6. Turner E, Irarrazaval JM, Valdes F, Dubernet J. Coartación Aórtica asociada a Arteria Lusoria. Rev Chil Cir. 1983;35:218-22.

7. Kieffer E, Bahnini A, Koskas F. Aberrant subclavian artery: surgical treatment in thirty-three adult patients. J Vasc Surg. 1994;19:100-9; discussion 110-1.

8. Lacroix V, Astarci P, Philippe D, Goffette P, Hammer F, Verhelst R, et al. Endovascular treatment of an aneurysmal aberrant right subclavian artery. J Endovasc Ther 2003; 10:190-4

9. Kamiya H, Knobloch K, Lotz J, Bog A, Lichtenberg A, Hagl C, et al. Surgical treatment of aberrant right subclavian artery (arteria lusoria) aneurysm using three different methods. Ann Thorac Surg. 2006; 82:187-90. 